\title{
ARRECADAÇÃO DE BEM VAGO ABANDONADO: ESTUDO PROCEDIMENTAL E PANORAMA DE EFEITOS
}

\section{PUBLIC APPROPRIATION OF IDLE PRIVATE PROPERTY: PROCEDURAL STUDY AND EFFECTS PANORAMA}

\author{
Felipe Jardim ${ }^{1}$ \\ Maria Ângela de Almeida Souza ${ }^{2}$ \\ Danielle de Melo Rocha ${ }^{3}$
}

\section{RESUMO}

Arrecadação de Bem Vago Abandonado (ABVA) é um instrumento do ordenamento jurídico brasileiro que, desde o Código Civil de 1916, legitima a possibilidade de incorporação da propriedade privada abandonada ao patrimônio público, observado o devido procedimento legal, bem como os direitos de defesa do proprietário. Apesar de ter viés patrimonial, ela pode ser utilizada, ao lado de outras ferramentas, como meio de proteção e o estímulo à função social da propriedade e da cidade, já que pune o proprietário do solo urbano ocioso com a perda da propriedade. Assim, esta pesquisa objetivou investigar o procedimento arrecadatório e os efeitos positivos e negativos para a sociedade, o poder público e o proprietário da aplicação da ABVA. O estudo indutivo foi desenvolvido a partir da elucidação documental da regulamentação legislativa, do mapeamento de casos concretos e da análise de dissertações, além de artigos especializados no tema. Foi posto em perspectiva que a ABVA é um instrumento importante para o planejamento urbano no combate à ociosidade imobiliária, mas que brechas legais requerem a complementaridade da ABVA por outros mecanismos a fim de impulsionar a função social da cidade e da propriedade.

Palavras-chave: Função social. Propriedade. Cidade. Arrecadação de Bem Vago Abandonado.

\footnotetext{
${ }^{1}$ Doutorando em Direito da Cidade (UERJ). Mestre em Desenvolvimento Urbano (UFPE). Bacharel em Direito (UNICAP). Universidade do Estado do Rio de Janeiro (UERJ) - Brasil. ORCID Id:

https://orcid.org/0000-0001-7364-3662 Lattes: http://lattes.cnpq.br/8691412568811905 E-mail: felipejardim@outlook.com

${ }^{2}$ Doutorado em História pela UFPE (2002). Departamento de Arquitetura e Urbanismo. Programa de Pósgraduação em Desenvolvimento Urbano. Universidade Federal de Pernambuco - UFPE - Brasil. ORCID ID: https://orcid.org/0000-0002-8808-1479 Lattes: http://lattes.cnpq.br/8276915082480930 E-mail: souza.mariaangela@gmail.com

${ }^{3}$ Profa. do Departamento de Arquitetura e Urbanismo - UFPE. Doutorado em Geografia e Ordenamento Territorial - Universidade Paris 3. Universidade Federal de Pernambuco - UFPE - Brasil. ORCID iD: https://orcid.org/0000-0002-7323-0187 Lattes: http://lattes.cnpq.br/5339482051252227 E-mail: dmrocha.ufpe@gmail.com
} 


\section{ABSTRACT}

Public Appropriation of Idle Private Property (ABVA) is an instrument of the Brazilian legal system that, since the Civil Code of 1916, legitimizes the possibility of incorporation of abandoned private property into public property, observing the due legal procedure, as well as the rights of defense of the owner. Despite having a patrimonial bias, it can be used, along with other tools, as a means of protection and to stimulate the social function of property and the city, since it punishes the owner of idle urban land with the loss of property. Thus, this research aimed to investigate the collection procedure and the positive and negative effects on society, the government and the owner of the ABVA application. The inductive study was developed from the documentary elucidation of the legislative regulation, the mapping of concrete cases and the analysis of dissertations, as well as articles specialized in the subject. It has been put in perspective that ABVA is an important instrument for urban planning in combating real estate idleness, but that legal loopholes require ABVA to complement each other in order to boost the social function of the city and property.

Keywords: Social function. Property. City. Collection of Vacant Abandoned Well.

\section{INTRODUÇÃO}

Este trabalho ${ }^{4}$ partiu do primeiro pressuposto de que o meio ambiente artificial deve, no mínimo, ofertar de forma digna, justa, igualitária, inclusiva, democrática e sustentável: a habitação, o trabalho, o lazer, a circulação, saúde, segurança, proteção, educação (funções sociais da cidade) e, para isto, a unidade menor, a propriedade, deve estar em consonância de uso e em equilíbrio com o contexto ao redor dela em prol da coletividade (função social da propriedade).

Por sua vez, o segundo pressuposto foi de que o direito à cidade, o qual teve formas diferentes de apropriação e difusão teórica e prática desde o marco da publicação de 1968 de Henry

\footnotetext{
${ }^{4}$ Artigo desenvolvido como desenvolvido como produto da dissertação: JARDIM, F. IPTU progressivo no tempo ou arrecadação de bem vago abandonado?: aplicabilidade de instrumentos jurídico-urbanísticos em imóveis ociosos do bairro do Recife. Dissertação (Mestrado). 2018. Universidade Federal de Pernambuco, Centro de Artes e Comunicação, Programa de Pós-graduação em Desenvolvimento Urbano. Disponível em: <https://repositorio.ufpe.br/handle/123456789/32193>.
} 
Lefebvre, é mais que o acesso de todos e todas ao consumo de equipamentos coletivos urbanos ${ }^{5}$, tratando-se também do direito de participar e intervir no modo de produção das cidades, sejam eles indivíduos ou coletivos, mais ou menos organizados ${ }^{6}$ - sendo este trabalho também uma ferramenta de participação.

Alinhado à estas visões, as últimas quatro décadas somaram esforços para consolidar o arcabouço jurídico brasileiro atual. Contudo, este panorama ideal, consolidado no ordenamento jurídico pátrio, nem sempre é respeitado, seja no âmbito da propriedade pública ou privada, quando imóveis dotados de infraestrutura urbana básica (abastecimento de água, esgotamento sanitário, coleta de resíduos sólidos, iluminação elétrica) estão ociosos por anos em prol da busca de lucros imobiliários, trazendo diversas consequências locais e regionais, como o risco de desabamento, a proliferação de pragas urbanas e a deterioração de espaços de importância histórica.

Importante destacar que a ociosidade de imóveis, problema no uso e/ou ocupação, foi conceitualmente construída neste trabalho a partir da adaptação de três subclassificações identificadas por Borde (2006 apud CLEMENTE, 2012, p. 31) e Sousa (2010 apud CLEMENTE, 2012, p. 38) e que são levantadas no ordenamento jurídico-urbanístico brasileiro (Estatuto da Cidade, art. 5):

\section{Figura 01 - Ociosidade de}

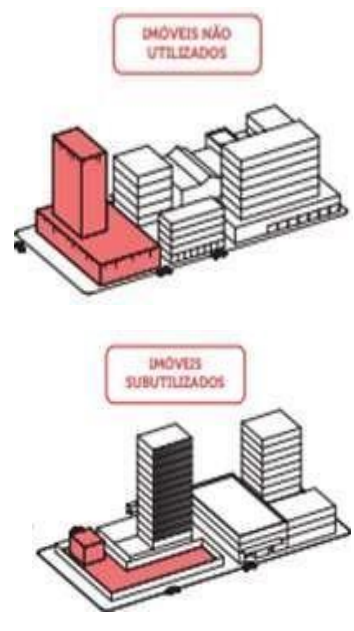

(i) imóveis não utilizados (desafetados, sem uso total), em que, quando há o comprometimento do estado de conservação (imóvel em estado precário, em processo de arruinamento ou já em ruínas), configura-se o critério subjetivo ${ }^{7}$ do abandono. Do contrário, quando aparentemente o estado de conservação não torna o uso inviável, o imóvel é classificado como fechado (totalmente);

(ii) imóveis subutilizados, que ainda possuem uso e/ou ocupação, mesmo que parciais ou temporários, mas com parâmetros de aproveitamento inferiores aos definidos em lei (Plano Diretor). Pode haver, ou não, o comprometimento do estado de conservação do imóvel, porém, pelo uso parcial, só poderiam ser considerados como fechados parcialmente;

\footnotetext{
${ }^{5}$ Como desenvolveu Manuel Castells (1972).

${ }^{6}$ Numa perspectiva de Henry Lefebvre (1991), Ermínia Maricato (1979, p. 83) e, principalmente, David Harvey (2013).

${ }^{7} \mathrm{O}$ critério objetivo é a presença de 05 anos ou mais de débitos fiscais.
} 

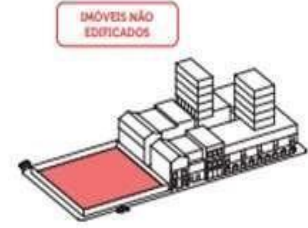

Ilustração: Prefeitura de São Paulo, 2015. (iii) imóveis não edificados (totalmente desocupados), sem qualquer edificação, que também podem ser classificados como fechados ou abandonados.

Assim, o tema central estudado consistiu na avaliação de uma das ferramentas que podem combater o problema da ociosidade de imóveis, qual seja a Arrecadação de Bem Vago Abandonado (ABVA): a perda da propriedade (que passará ao município após o devido processo administrativo) do imóvel urbano privado abandonado e sem possuidor cujo proprietário não possua a intenção de conservá-lo em seu patrimônio e tenha 05 anos ou mais de débitos fiscais podendo ser destinado aos serviços públicos e aos programas habitacionais, por exemplo, tudo em conformidade com a regulamentação procedimental específica de cada município e com o Código Civil de 2002.

Após apresentar fundamento na função social, este trabalho realizou a identificação e a análise do acervo legislativo relativo ao tema (Constituição Federal, Código Civil, Lei e Decreto da Regularização Fundiária, Estatuto da Cidade) - detalhando os requisitos, os procedimentos, os prazos e as especificidades. Em seguida, a partir da produção bibliográfica (artigos, livros, dissertações), foi possível cumprir com o objetivo de investigar os efeitos positivos e negativos para a sociedade, o poder público e o proprietário da aplicação da ABVA.

Dentre os resultados principais, destaca-se que ela é um mecanismo que, apesar do alicerce no direito patrimonial, serve como perspectiva da garantia das funções sociais da cidade e da propriedade (imóvel, privada e urbana), indispensável ao direito à cidade, desde que atue em conjunto com outras ferramentas jurídico-urbanísticas.

\section{APONTAMENTOS SOBRE A FUNÇÃO SOCIAL NO BRASIL}

A função social da cidade e da propriedade são construções conceituais fluidas, que passaram por diversas transformações ao longo de cada período da história e de cada sociedade.

Especialmente após a influência religiosa, como a dada por Santo Tomás de Aquino (1265) e pelas Encíclicas Papais, como a Rerum Novarum (1891) e Centesimus Annus (1991); as contribuições do francês León Deguit (1912), que inaugurou juridicamente a função social da propriedade ao apresentar as transformações do direito privado; o constitucionalismo social, como ocorrido no México (1917) e na Alemanha (Weimar, 1919), que tutelaram, em âmbito 
constitucional, a socialização da propriedade; e os estudos de Le Corbusier (1933), a cidade e a propriedade moderna passaram a incorporar o cerne da função social, que foi atualizado na cidade contemporânea.

Basicamente, o centro dessa composição é que o proprietário tem o dever de utilizar a coisa para atender a um fim social" a fim de "perseguir o equilíbrio entre o direito de propriedade e o direito social e conciliar as duas ordens de interesses" conforme regência da lei (FORNEROLLI, 2014, p. 160-162).

Trata-se de finalidade com repercussão direta e indireta nas funções sociais da cidade, sejam elas funções urbanísticas (habitação, trabalho, lazer e mobilidade - apontadas por Le Corbusier, na Carta de Atenas de 1933), de cidadania (as anteriores, além de educação, saúde, segurança e proteção social) ou de gestão (prestação de serviços, planejamento, preservação do patrimônio cultural, sustentabilidade urbana), como identificam Garcias e Bernardini (2008, p. 10).

No Brasil, a Carta Magna de 1988 inaugura o Estado Democrático de Direito, que inclui dentre seus fundamentos a dignidade da pessoa humana em seu art. 1으. III, constituindo como objetivos fundamentais, dentre outros, construir uma sociedade livre, justa e solidária (art. 3o, I), erradicar a pobreza e a marginalização (art. 3ำ, III), promover o bem de todos, sem preconceitos de origem, raça, sexo, cor, idade e quaisquer outras formas de discriminação (art. 3o, IV).

A propriedade é garantida no art. $5^{\circ}, X X I I$, seguida do dever desta de atender a função social (art. $5^{\circ}$, XXIII). A função social, além de estar no capítulo de direitos e garantias fundamentais, é tratada como como princípio geral de ordem econômica (art. 170, III). É um dos fatos que distingue a presente Constituição da anterior e repercute em duas faces de transformação da tutela de propriedade: o direito fundamental individual e o direito fundamental social.

Como influência das décadas de luta do Movimento Nacional da Reforma Urbana, foi na Constituição de 1988 em que se inaugurou um capítulo exclusivo para a "Política Urbana" (art. 182 e 183), sob o Título "Da Ordem Econômica e Financeira".

A Carta de 1988 também inovou ao categorizar diferentes demarcações quanto a propriedade urbana (art. 182 e seguintes) e quanto a rural (art. 184 e ss.). 0 art. 186, em seus incisos I a IV, prescrevem os critérios para o atendimento à função social, condicionando a propriedade individual a interesses não individuais, consolidando o direito à cidade. 0 art. 182, § 2ํ, determina 
que a propriedade urbana cumpre com sua função social quando atende o seu Plano Diretor do município.

Se o titular do direito de propriedade não der a destinação social ao objeto de seu direito, a Carta Maior ordena ${ }^{8}$ a aplicação do art. 182, §4으, que prevê a desapropriação de propriedade urbana não edificada, subutilizada ou não-utilizada, caso seu proprietário não promova adequado aproveitamento de acordo com o Plano Diretor municipal.

Desta forma, as sanções constitucionais não dependem da discricionariedade do administrador. O Estado tem, na verdade, o dever de aplicá-las, sob pena de omissão administrativa (SANTOS; OLIVEIRA, 2016, p. 123).

Então, o direito de propriedade passa a ter polo ativo e passivo, com finalidades, direitos, deveres, obrigações e ônus, impondo "ao proprietário - ou a quem detém o controle, na empresa o dever de exercê-lo em benefício de outrem e não, apenas, de não o exercer em prejuízo de outrem" (GRAU, 2001, p. 275).

Ainda, destaca-se que, por força do art. 170, III e IV, a função social da propriedade está no mesmo patamar da livre concorrência. Assim, o mercado brasileiro, incluindo o imobiliário, é livre, mas deve seguir algumas formas, bem como auxiliar na concretização dos objetivos do Estado, questão esta que é fundamentada na função social da propriedade. Contudo, apesar do Estado ser definido constitucionalmente como agente normativo e regulador da atividade econômica, exercendo as funções de fiscalização, incentivo e planejamento, isto é determinante para o setor público e indicativo para o setor privado (art. 174).

Destaca-se que na análise sobre a propriedade por vários doutrinadores brasileiros sintetizada por Henrique Franceschetto e Paulo Grando (2016, p. 14), entende-se que "a doutrina brasileira majoritária atual tende a convergir no sentido de que a função social da propriedade não deve ser encarada apenas como uma limitação ao direito de propriedade, mas sim como uma parte integrante deste, sem a qual a própria propriedade deixa de existir".

\footnotetext{
${ }^{8}$ Apesar de no texto constitucional constar que "É facultado ao Poder Público municipal, mediante lei específica para área incluída no Plano Diretor, exigir, nos termos da lei federal, do proprietário do solo urbano não edificado, subutilizado ou não utilizado, que promova seu adequado aproveitamento", entende-se, segundo Denaldi (2015a, p. 39 apud BRAJATO, 2015, p. 77) e Filho e Denaldi (2012, p. 97 e 98 apud BRAJATO, 2015, p. 77), que trata-se de um poder-dever, sendo obrigatório quando houver necessidade, em especial para cumprimento de direitos fundamentais. Além disso, o Estatuto da Cidade trata-se de norma de ordem pública (art. $1^{\circ}$, parágrafo único), ou seja, independem da vontade das partes (administrador e proprietário).
} 
Em suma, entende-se a função social como mais que um elemento limitador da propriedade, um verdadeiro elemento fundamental ou requisito básico. Seguindo este posicionamento, a Constituição Federal de 1988 e as legislações infraconstitucionais do Brasil foram elaboradas.

Após anos de suspensão e diversos esforços, em 2001, o Projeto de Lei no 5.788/90, foi transformado no Estatuto da Cidade ${ }^{9}$, regulamentando os arts. 182 e 183 da Constituição Federal e influenciando o Código Civil de 2002. Ele vem superar quase "um século de atraso se comparado às experiências europeias no que diz respeito ao uso de instrumentos urbanísticos para regular socialmente o mercado imobiliário e fazer políticas de compensação social através da política urbana" (QUINTO JUNIOR, 2003, p. 193).

Nele foram estabelecidas diretrizes gerais de ordenamento do pleno desenvolvimento das funções sociais da cidade e da propriedade urbana (art. $\left.2^{2}\right)^{10}$. Pelo art. 39 do Estatuto da Cidade,

\footnotetext{
$\overline{{ }^{9} \text { Também precedido pelos Projetos }}$ de Lei no 775/83 e no 2.191/1989.

10 I - garantia do direito a cidades sustentáveis, entendido como o direito à terra urbana, à moradia, ao saneamento ambiental, à infraestrutura urbana, ao transporte e aos serviços públicos, ao trabalho e ao lazer, para as presentes e futuras gerações;

IV - planejamento do desenvolvimento das cidades, da distribuição espacial da população e das atividades econômicas do Município e do território sob sua área de influência, de modo a evitar e corrigir as distorções do crescimento urbano e seus efeitos negativos sobre o meio ambiente;

$\mathrm{V}$ - oferta de equipamentos urbanos e comunitários, transporte e serviços públicos adequados aos interesses e necessidades da população e às características locais;

VI - ordenação e controle do uso do solo, de forma a evitar:

a) a utilização inadequada dos imóveis urbanos;

b) a proximidade de usos incompatíveis ou inconvenientes;

c) o parcelamento do solo, a edificação ou o uso excessivos ou inadequados em relação à infraestrutura urbana;

d) $[\ldots]$

e) a retenção especulativa de imóvel urbano, que resulte na sua subutilização ou não utilização;

f) a deterioração das áreas urbanizadas;

IX - justa distribuição dos benefícios e ônus decorrentes do processo de urbanização;

$X$ - adequação dos instrumentos de política econômica, tributária e financeira e dos gastos públicos aos objetivos do desenvolvimento urbano, de modo a privilegiar os investimentos geradores de bem-estar geral e a fruição dos bens pelos diferentes segmentos sociais;

XI - recuperação dos investimentos do Poder Público de que tenha resultado a valorização de imóveis urbanos:

XII - proteção, preservação e recuperação do meio ambiente natural e construído, do patrimônio cultural, histórico, artístico, paisagístico e arqueológico;

XVII - estímulo à utilização, nos parcelamentos do solo e nas edificações urbanas, de sistemas operacionais, padrões construtivos e aportes tecnológicos que objetivem a redução de impactos ambientais e a economia de recursos naturais.

XVIII - tratamento prioritário às obras e edificações de infraestrutura de energia, telecomunicações, abastecimento de água e saneamento. (Incisos selecionados pelo autor)
} 
determina-se que a função social da propriedade urbana é cumprida quando se atende aos requisitos fundamentais de "ordenação da cidade expressas no Plano Diretor, assegurando o atendimento das necessidades dos cidadãos quanto à qualidade de vida, à justiça social e ao desenvolvimento das atividades econômicas", em observação aos mandamentos do art. 2ำ da mesma lei.

Nota-se que o Estatuto da Cidade não previu a ABVA como meio de promoção da função social, mas no ano seguinte à entrada em vigor dele, adveio o Código Civil de 2002, que passa a respeitar todo o acervo normativo anterior e, implicitamente, introduz a ABVA como mais um meio de conquistar os ideais previstos pelo Estatuto.

\section{FUNDAMENTAÇÃO LEGAL E PROCEDIMENTOS DA ARRECADAÇÃO DE BEM VAGO ABANDONADO}

Quanto à natureza jurídica, ainda pairam dúvidas. Mota (2017), por exemplo, defende que o instituto tem natureza híbrida porque é "assemelhado com a usucapião social [modo de aquisição coletivo da propriedade], simultaneamente, com a 'desapropriação indireta' diante da exigência de pagamento de uma "justa indenização devida ao proprietário".

Entretanto, o autor deste trabalho não concorda com a segunda parte da afirmação acima, posto que a indenização seria forma de premiar o proprietário do solo urbano que descumpre com a função social, além dela não ser prevista nos instrumentos que regulam o tema. $O$ instituto talvez possa ser mais semelhante à uma espécie de "doação presumida" (que já serve para a doação de órgãos) ou uma transformação da "herança jacente" em ato inter vivos (em alguns casos).

Este instituto já estava previsto no ordenamento jurídico brasileiro como meio de perda do direito de propriedade desde o Código Civil de 1916, no art. 589, inciso III e no $\S 2^{\circ}$ do mesmo artigo, o qual prescrevia, de acordo com Decreto do Poder Legislativo no 3.725, de 1919, a seguinte redação: "O imóvel abandonado arrecadar-se-á como bem vago, passará, dez anos depois, ao domínio do Estado, onde se achar, ou da União, se estiver no Distrito Federal ou em território não constituído em estado". Mais tarde, em 1981, em razão da Lei no 6.969/81, a redação do artigo foi alterada ${ }^{11}$.

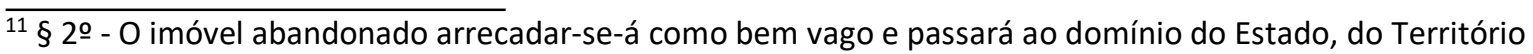
ou do Distrito Federal se se achar nas respectivas circunscrições:
} 


\section{Código Civil de 2002}

Com o advento da Constituição Federal de 1988, o Código Civil de 2002 (Lei no 10.406/2002) define a propriedade como um direito real (art. 1225, I) em que, dentre outras considerações, aborda o conteúdo do direito de propriedade e postula a necessária função social da propriedade como instrumento do projeto constitucional de defesa ao meio ambiente ${ }^{12}$.

O Código Civil de 2002, no Parágrafo Único, do art. 2.035, também declara que "nenhuma convenção prevalecerá se contrariar preceitos de ordem pública, tais como os estabelecidos por este Código para assegurar a função social da propriedade e dos contratos". O Código também é responsável por elencar como meio de perda da propriedade o abandono (art. 1275, inciso III) e por força do art. $1.276^{13}$, traz uma nova redação ao instituto.

Neste ponto, merecem destaque as condições impostas pelo Código Civil de 2002 para que haja configuração do abandono: ato unilateral em que o titular (conforme Cartório de Registro de Imóveis), abre mão dos direitos sobre o bem de forma voluntária, intencional e sem manifestação expressa (GONÇALVES, 2002, p. 118), a ser comprovado por diversos meios, posto que o mesmo não se configura apenas como desuso ou mero desprezo físico pelo bem vago (critério subjetivo/complementar), dentre eles o meio que não cabe disposição em contrário (presunção absoluta, critério objetivo/principal expresso na lei) de existência de pelo menos um tipo de débito

a) 10 (dez) anos depois, quando se tratar de imóvel localizado em zona urbana;

b) 3 (três) anos depois, quando se tratar de imóvel localizado em zona rural.

${ }^{12}$ Art. 1.228. O proprietário tem a faculdade de usar, gozar e dispor da coisa, e o direito de reavê-la do poder de quem quer que injustamente a possua ou detenha.

$\S$ 1으 $\mathrm{O}$ direito de propriedade deve ser exercido em consonância com as suas finalidades econômicas e sociais e de modo que sejam preservados, de conformidade com o estabelecido em lei especial, a flora, a fauna, as belezas naturais, o equilíbrio ecológico e o patrimônio histórico e artístico, bem como evitada a poluição do ar e das águas.

$\S 2^{\circ}$ São defesos os atos que não trazem ao proprietário qualquer comodidade, ou utilidade, e sejam animados pela intenção de prejudicar outrem.

$\S 3^{\circ} \mathrm{O}$ proprietário pode ser privado da coisa, nos casos de desapropriação, por necessidade ou utilidade pública ou interesse social, bem como no de requisição, em caso de perigo público iminente. [...] (grifos nossos)

${ }^{13}$ Art. 1.276. O imóvel urbano que o proprietário abandonar, com a intenção de não mais o conservar em seu patrimônio, e que se não encontrar na posse de outrem, poderá ser arrecadado, como bem vago, e passar, três anos depois, à propriedade do Município ou à do Distrito Federal, se se achar nas respectivas circunscrições.

$\S 1^{\circ}$. O imóvel situado na zona rural, abandonado nas mesmas circunstâncias, poderá ser arrecadado, como bem vago, e passar, três anos depois, à propriedade da União, onde quer que ele se localize.

$\S 2^{\circ}$. Presumir-se-á de modo absoluto a intenção a que se refere este artigo, quando, cessados os atos de posse, deixar o proprietário de satisfazer os ônus fiscais. 
fiscal devidamente constituído - não só de IPTU, mas também de "eventual contribuição de melhoria ou a novel contribuição para o serviço de iluminação pública"; cumulado ao fato de que não haja possuidor posto que a posse indicaria o cumprimento da função social por terceiro com possibilidade de usucapir o bem (SANHUDO, 2007, p. 101).

Deste critério objetivo não cabe disposição em contrário, pois trata-se de uma presunção absoluta ${ }^{14}$, mas sem excluir a possibilidade de respeito aos prazos de defesa administrativa - e, eventualmente, judicial -, pois isso tornaria o processo arrecadatório nulo. Já o critério subjetivo seria um critério auxiliar a fim de identificar, por meio da observação em pesquisa de campo da prefeitura, os imóveis com problemas de conservação, o que seria um indício do abandono a ser posteriormente confirmado pela verificação do critério principal nos sistemas fiscais do município.

Retomando o processo arrecadatório, da leitura do art. 1276, do Código Civil, depreendese que o imóvel não pode ter possuidor, direto ou indireto, regular ou irregular, posto que a posse indicaria o cumprimento da função social por terceiro com possibilidade de usucapir o bem. Também se entende que deve haver a intenção do proprietário não mais querer conservar o bem em seu patrimônio. Assim, quando o imóvel está em uso (regular ou irregular - sem autorização do proprietário e/ou da prefeitura; permanente ou temporário; total ou parcial) do bem, não é cabível a Arrecadação de Bem Vago Abandonado, da mesma forma que obras de recuperação de fachada e/ou estrutura, em andamento ou concluídas, tornam-se empecilho ao instrumento.

Após verificados os critérios subjetivo e objetivo, o poder público municipal (ou distrital) deve realizar a declaração de vacância do bem após um processo administrativo. Se neste processo o proprietário não manifestar interesse no bem (ingressando com projeto de obras no setor responsável da prefeitura, pagar ou comprovar o pagamento dos débitos fiscais), a municipalidade, independente da discricionariedade (interesse e conveniência do prefeito) ${ }^{15}$, terá a posse imediata

\footnotetext{
${ }^{14}$ Em especial, o tema da presunção foi abordado pelo Enunciado $n^{\circ} 243$ do Conselho da Justiça Federal: "A presunção de que trata o $\S 2$ 으 do art. 1.276 não pode ser interpretada de modo a contrariar a norma-princípio do art. 150, inc. IV, da Constituição da República" (BRASIL, 2006) - qual seja a vedação ao confisco de bens em razão da ordem tributária", já que o instituto presume o abandono também por causa do não cumprimento das obrigações fiscais. Este fator levou a considerar a presunção de abandono em razão dos débitos fiscais inconstitucional por parte de Antonio Carvalho (sem data) e Cristiano Chaves de Farias (2015) em razão da competência da União de estabelecer os meios de perda da propriedade e em prol do direito individual do cidadão de dispor e fruir do bem. Como esta discussão de constitucionalidade não é foco deste trabalho, admite-se como válida a teoria afirmada por Armando Lotti (2006), Procuradoria-geral do Município de Porto Alegre/RS (2012), Vladimir Freitas (2013); Leandro Cunha e Terezinha Domingos (2010) e Talden Farias (2018) que afirmam a constitucionalidade em razão do interesse coletivo.

${ }^{15}$ Posto que é um ato administrativo vinculado, inclusive cabendo ação de improbidade administrativa caso não respeitada a lei.
} 
não-própria ${ }^{16}$ do bem em arrecadação e uma expectativa de direito à propriedade (MIRANDA, 1955, p. 135 apud PGMPOA, 2012). Essa expectativa só será transformada efetivamente em direito à propriedade e posse própria por parte do poder público após 03 (três) anos da declaração de vacância (LOTTI, 2006).

\section{Lei e Decreto da Regularização Fundiária}

Em 2017, a ABVA foi regulamentada pela Lei $n^{\circ} 13.465$ (Lei da Regularização Fundiária Urbana, Rural e na Amazônia Legal) através do Título "da Regularização Fundiária Urbana" - a Reurb, que "abrange medidas jurídicas, urbanísticas, ambientais e sociais destinadas à incorporação dos núcleos urbanos informais ao ordenamento territorial urbano e à titulação de seus ocupantes" (art. $9^{\circ}$ ) a partir da formulação e desenvolvimento no espaço urbano pelos poderes públicos de "políticas de suas competências de acordo com os princípios de sustentabilidade econômica, social e ambiental e ordenação territorial, buscando a ocupação do solo de maneira eficiente, combinando seu uso de forma funcional” (art. $9^{\circ}, \S 1^{\circ}$ ).

Por força do art. $10^{17}$, foram estabelecidos os objetivos da Reurb. A lei também estabelece (art. 13) que a Reurb pode se dar por meio de Interesse Social (Reurb-S), com "regularização fundiária aplicável aos núcleos urbanos informais ocupados predominantemente por população de baixa renda, assim declarados em ato do Poder Executivo municipal"; ou Interesse Específico

\footnotetext{
${ }^{16}$ Sem animus domini, com poderes limitados até que haja transformação em posse própria (com animus domini) após três anos da declaração de vacância.

17 Art. 10. Constituem objetivos da Reurb, a serem observados pela União, Estados, Distrito Federal e Municípios:

I - identificar os núcleos urbanos informais que devam ser regularizados, organizá-los e assegurar a prestação de serviços públicos aos seus ocupantes, de modo a melhorar as condições urbanísticas e ambientais em relação à situação de ocupação informal anterior;

II - criar unidades imobiliárias compatíveis com o ordenamento territorial urbano e constituir sobre elas direitos reais em favor dos seus ocupantes;

III - ampliar o acesso à terra urbanizada pela população de baixa renda, de modo a priorizar a permanência dos ocupantes nos próprios núcleos urbanos informais regularizados;

IV - promover a integração social e a geração de emprego e renda;

$\mathrm{V}$ - estimular a resolução extrajudicial de conflitos, em reforço à consensualidade e à cooperação entre Estado e sociedade;

VI - garantir o direito social à moradia digna e às condições de vida adequadas;

VII - garantir a efetivação da função social da propriedade;

VIII - ordenar o pleno desenvolvimento das funções sociais da cidade e garantir o bem-estar de seus habitantes;

IX - concretizar o princípio constitucional da eficiência na ocupação e no uso do solo;

$X$ - prevenir e desestimular a formação de novos núcleos urbanos informais;

$\mathrm{XI}$ - conceder direitos reais, preferencialmente em nome da mulher;

XII - franquear participação dos interessados nas etapas do processo de regularização fundiária.
} 
(Reurb-E), com "regularização fundiária aplicável aos núcleos urbanos informais ocupados por população não qualificada na hipótese de que trata o inciso I deste artigo".

O mesmo artigo dispõe no $\S 4^{\circ}$ que, "na Reurb, os Municípios e o Distrito Federal poderão admitir o uso misto de atividades como forma de promover a integração social e a geração de emprego e renda no núcleo urbano informal regularizado."

Já $\mathrm{o}$ art. 14 determina os legitimados ${ }^{18}$ para requerer a abertura do procedimento administrativo da Reurb, instrumento jurídico que poderá ser empregado sem prejuízo de outros que se apresentem adequados.

Como novidade conceituais e procedimentais na Lei da Regularização Fundiária (art. 15, IV; 64 e 65$)^{19}$, em relação ao Código Civil de 2002: (i) exclui-se a propriedade pública como alvo de

\footnotetext{
${ }^{18}$ Art. 14. Poderão requerer a Reurb:

I - a União, os Estados, o Distrito Federal e os Municípios, diretamente ou por meio de entidades da administração pública indireta;

II - os seus beneficiários, individual ou coletivamente, diretamente ou por meio de cooperativas habitacionais, associações de moradores, fundações, organizações sociais, organizações da sociedade civil de interesse público ou outras associações civis que tenham por finalidade atividades nas áreas de desenvolvimento urbano ou regularização fundiária urbana;

III - os proprietários de imóveis ou de terrenos, loteadores ou incorporadores;

IV - a Defensoria Pública, em nome dos beneficiários hipossuficientes; $\mathrm{e}$

V - o Ministério Público.
}

${ }^{19}$ Art. 64. Os imóveis urbanos privados abandonados cujos proprietários não possuam a intenção de conservá-los em seu patrimônio ficam sujeitos à arrecadação pelo Município ou pelo Distrito Federal na condição de bem vago.

$\S 1^{\circ} \mathrm{A}$ intenção referida no caput deste artigo será presumida quando o proprietário, cessados os atos de posse sobre o imóvel, não adimplir os ônus fiscais instituídos sobre a propriedade predial e territorial urbana, por cinco anos.

§ 2o O procedimento de arrecadação de imóveis urbanos abandonados obedecerá ao disposto em ato do Poder Executivo municipal ou distrital e observará, no mínimo:

I - abertura de processo administrativo para tratar da arrecadação;

II - comprovação do tempo de abandono e de inadimplência fiscal;

III - notificação ao titular do domínio para, querendo, apresentar impugnação no prazo de trinta dias, contado da data de recebimento da notificação.

$\S 3^{\circ} \mathrm{A}$ ausência de manifestação do titular do domínio será interpretada como concordância com a arrecadação.

$\S 4^{\circ}$ Respeitado o procedimento de arrecadação, o Município poderá realizar, diretamente ou por meio de terceiros, os investimentos necessários para que o imóvel urbano arrecadado atinja prontamente os objetivos sociais a que se destina.

$\S 5^{\circ} \mathrm{Na}$ hipótese de o proprietário reivindicar a posse do imóvel declarado abandonado, no transcorrer do triênio a que alude o art. 1.276 da Lei $n^{\circ}$ 10.406, de 10 de janeiro de 2002 (Código Civil), fica assegurado ao Poder Executivo municipal ou distrital o direito ao ressarcimento prévio, e em valor atualizado, de todas as despesas em que eventualmente houver incorrido, inclusive tributárias, em razão do exercício da posse provisória. (grifos nossos)

Art. 65. Os imóveis arrecadados pelos Municípios ou pelo Distrito Federal poderão ser destinados aos programas habitacionais, à prestação de serviços públicos, ao fomento da Reurb-S ou serão objeto de 
processo arrecadatório; (ii) especifica-se o prazo dos débitos fiscais para a presunção absoluta de abandono em, no mínimo, 05 anos; (iii) estipula-se condições para o regulamento municipal: a) a necessidade de processo administrativo (com os devidos direitos de defesa do proprietário, até porque o não pagamento de ônus fiscal pode ter se dado em razão de imunidade ou isenção tributária); b) a comprovação do requisito temporal e fiscal; c) notificação do titular do domínio; e d) prazo de 30 dias para este apresentar impugnação (comprovando os pagamentos devidos) sob pena de ser considerada a concordância com a arrecadação. Este mandamento está consoante ao Enunciado 242/2016, do Conselho da Justiça Federal: "A aplicação do art. 1.276 depende do devido processo legal, em que seja assegurado ao interessado demonstrar a não-cessação da posse" (BRASIL, 2006).

Também é estipulado que (iv) após o procedimento de arrecadação, autoriza-se o município, direta ou indiretamente realizar investimentos necessários para o imóvel cumpra com a função social; (v) fica estabelecido que, se após a declaração de abandono realizada pelo processo administrativo e antes do prazo de 03 anos, o proprietário reivindicar a posse do imóvel declarado abandonado, o poder público fica assegurado de ser ressarcido nos valores investidos a fim de evitar o enriquecimento ilícito pela retomada do bem vago valorizado durante a posse provisória do município - com isso, confirma-se que, mesmo arrecadado, o bem ainda é de propriedade privada; e, por fim, (vi) determina-se que algumas possíveis finalidades para os bens arrecadados: "programas habitacionais, à prestação de serviços públicos, ao fomento da Reurb-S ou serão objeto de concessão de direito real de uso a entidades civis que comprovadamente tenham fins filantrópicos, assistenciais, educativos, esportivos ou outros, no interesse do Município ou do Distrito Federal" (art. 65).

O Decreto no 9.310, de 15 de março de 2018 instituiu normas gerais e os procedimentos aplicáveis à Regularização Fundiária Urbana, incluindo os da Arrecadação de Bem Vago Abandonado 20 .

concessão de direito real de uso a entidades civis que comprovadamente tenham fins filantrópicos, assistenciais, educativos, esportivos ou outros, no interesse do Município ou do Distrito Federal.

20 Art. 73. Os imóveis urbanos privados abandonados cujos proprietários não possuam a intenção de conservá-los em seu patrimônio ficam sujeitos à arrecadação pelo Município ou pelo Distrito Federal na condição de bem vago. § 1ㅇ A intenção referida no caput será presumida quando o proprietário, cessados os atos de posse sobre o imóvel, não adimplir os ônus fiscais instituídos sobre a propriedade predial e territorial urbana, pelo prazo de cinco anos. § 2 o O procedimento de arrecadação de imóveis urbanos abandonados observará o disposto em ato do Poder Executivo municipal ou distrital e, no mínimo: 
Com esta redação, acrescenta-se condições para a notificação do titular: deve ser feita por via postal, "considerada efetuada quando comprovada a entrega nesse endereço" ( $3^{\circ}$ ); e, caso não localizados, a notificação ocorrerá por edital "a localização e a descrição do imóvel a ser arrecadado, para que apresentem impugnação no prazo de trinta dias, contado da data da notificação" $\left(\S 4^{\circ}\right)$.

Por fim, o Decreto abordado estipula que quem pode determinar a abertura do processo administrativo é o "Poder Público municipal ou distrital ou a requerimento de terceiro interessado" $\left(\S 5^{\circ}\right)$. Em termos práticos, a prefeitura precisa prever um sistema de recebimento de denúncias para dar continuidade ao sistema.

Em suma, a ABVA é uma ferramenta jurídica que tem potencial de transformação urbanística e social ao induzir que o proprietário de imóvel urbano abandonado identificado através de um critério subjetivo/complementar, ou seja, sem uso e com comprometimento estrutural, fato ratificado pelo autossuficiente critério objetivo de 05 anos ou mais de débitos fiscais, tome iniciativa para transformar a má realidade do imóvel em processo de arrecadação com um que cumpra a função social da propriedade e da cidade. Em outra hipótese, o poder público, ao ter a posse definitiva no prazo de 03 anos após a declaração de vacância do bem e sem manifestação de

I - abertura de processo administrativo para tratar da arrecadação; II - comprovação do tempo de abandono e de inadimplência fiscal; e III - notificação ao titular do domínio para, querendo, apresentar impugnação no prazo de trinta dias, contado da data de recebimento da notificação.

§ 3 A notificação do titular de domínio será feita por via postal com aviso de recebimento, no endereço que constar do cadastro municipal ou distrital, e será considerada efetuada quando comprovada a entrega nesse endereço.

$\S 4$ ㅇ Os titulares de domínio não localizados serão notificados por edital, do qual deverão constar, de forma resumida, a localização e a descrição do imóvel a ser arrecadado, para que apresentem impugnação no prazo de trinta dias, contado da data notificação. § 50 A abertura do processo administrativo de que trata o inciso I do § 2ㅇ será determinada pelo Poder Público municipal ou distrital ou a requerimento de terceiro interessado. § 6으 A ausência de manifestação do titular de domínio será interpretada como concordância com a arrecadação.

$\S 70$ Respeitado o procedimento de arrecadação, o Município poderá realizar, diretamente ou por meio de terceiros, os investimentos necessários para que o imóvel urbano arrecadado atinja prontamente os objetivos sociais a que se destina. $\S 8$ o Na hipótese de o proprietário reivindicar a posse do imóvel declarado abandonado, no transcorrer do prazo de três anos a que se refere o art. 1.276 da Lei no 10.406, de 2002 - Código Civil, fica assegurado ao Poder Público municipal ou distrital o direito ao ressarcimento prévio e em valor atualizado das despesas em que houver incorrido, inclusive aquelas tributárias, em razão do exercício da posse provisória.

Art. 74. Os imóveis arrecadados pelos Municípios ou pelo Distrito Federal poderão ser destinados aos programas habitacionais, à prestação de serviços públicos, ao fomento da Reurb-S ou serão objeto de concessão de direito real de uso a entidades civis que comprovadamente tenham fins filantrópicos, assistenciais, educativos, esportivos ou outros, no interesse do Município ou do Distrito Federal. 
interesse do proprietário, tem o poder-dever de dar o referido cumprimento da função social. Abaixo, segue figura com resumo esquemático do procedimento de aplicação da ABVA (Figura 02):

Figura 02 - Esquematização da aplicação da ABVA

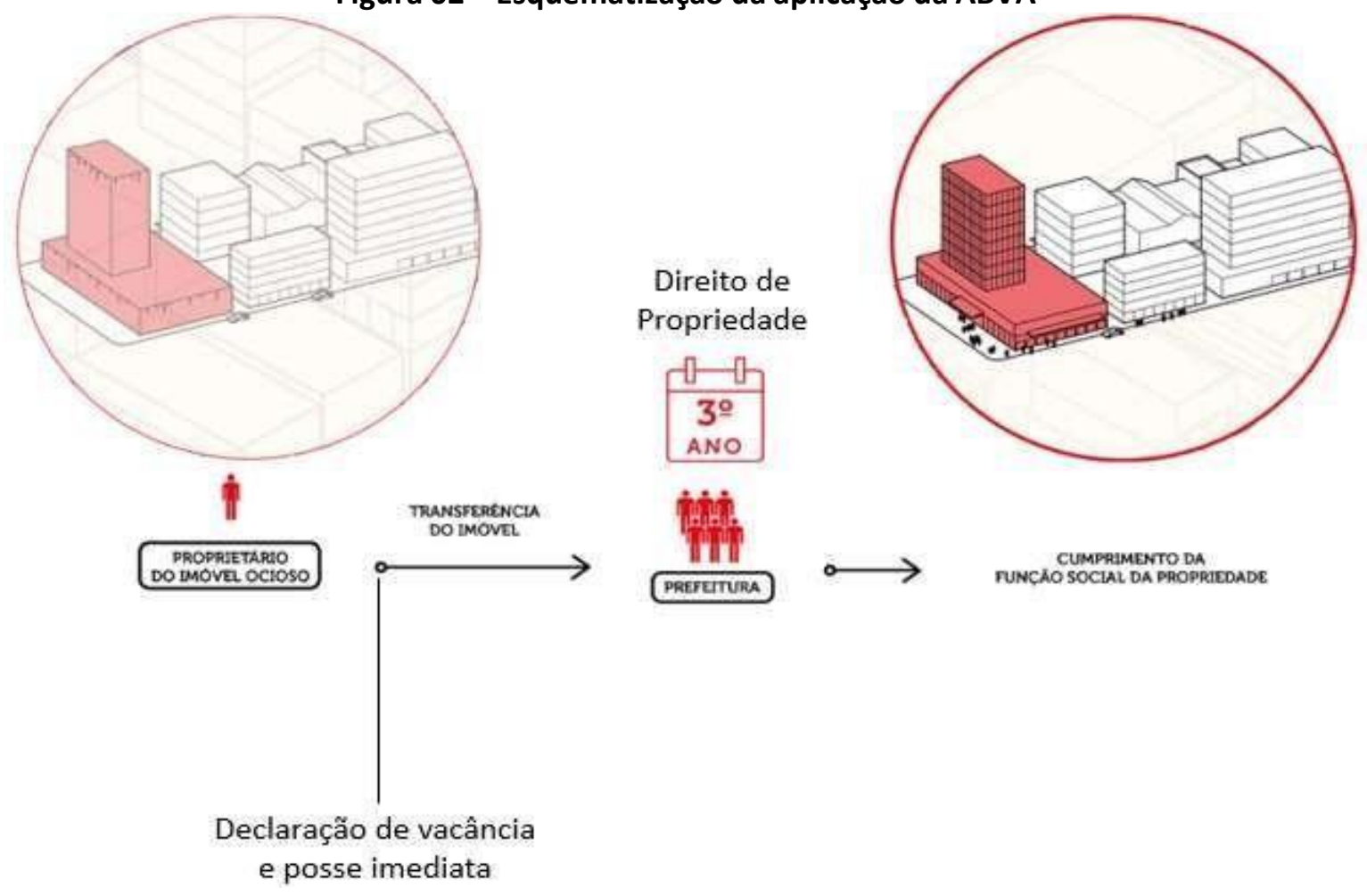

Fonte: Autor, 2018.

[Adaptação de ilustrações da Cartilha da função social da propriedade - Prefeitura de São Paulo, 2015]

Visto isso, passa-se à procura de municípios com regulamentação da ABVA, bem como a instauração de processos administrativos ou judiciais relativos ao objeto em discussão.

\section{Registro de casos}

Com base nos buscadores ${ }^{21}$ VLex e Jusbrasil, em dados de trabalhos acadêmicos, em notícias e em informações de prefeitura/câmara de vereadores disponíveis na internet, foi possível mapear a regulamentação e aplicação da ABVA no Brasil (Quadro 01).

Resumidamente, nos julgados sobre o tema observa-se que a falta de regulamentação específica, a vedação ao confisco, a proteção fundamental à propriedade e a necessidade de

\footnotetext{
${ }^{21}$ Pesquisa de julgados sobre "arrecadação de bem vago abandonado" e "artigo 1.276, § 2o, do Código Civil", nos Tribunais de Justiça Estaduais, no Superior Tribunal de Justiça e no Supremo Tribunal Federal, sem limite de tempo.
} 
respeito ao devido procedimento legal foram acolhidos como argumentos prósperos de defesa do proprietário.

Também se nota que pequena parte dos 5.570 municípios brasileiros realizou a regulamentação do tema e a maioria fez antes da entrada em vigor da Lei (11 de julho de 2017) e do Decreto da Regularização Fundiária Urbana (15 de março de 2018). Ou seja, ainda precisam passar por um controle legislativo de recepção ou não.

\section{Quadro 01 - ABVA em municípios brasileiros}

\begin{tabular}{|c|c|c|}
\hline MUNICÍPIO & LEGISLAÇÃO & REGISTRO DE CASOS \\
\hline $\begin{array}{l}\text { Manaus/A } \\
\text { M }\end{array}$ & $\begin{array}{l}\text { Lei no 166, de } 13 \text { de setembro de } \\
2005\end{array}$ & $\begin{array}{l}\text { TJ-AM - Processo Ordinário no } \\
\text { 062.184070.2016.8.04.0001 }\end{array}$ \\
\hline $\begin{array}{l}\text { Camaquã/R } \\
\text { S }\end{array}$ & $\begin{array}{l}\text { Lei no } 785 \text {, de } 30 \text { de dezembro de } \\
2005\end{array}$ & \\
\hline Amparo/SP & \multirow{4}{*}{ Não identificado } & $\begin{array}{c}\text { TJ-SP - Apelação: } 1715485520078260000 \\
\text { SP 0171548-55.2007.8.26.0000 }\end{array}$ \\
\hline $\begin{array}{c}\text { Nazaré } \\
\text { Paulista/SP }\end{array}$ & & $\begin{array}{c}\text { TJ-SP - Apelação: } \\
\text { 01751043120088260000 SP 0175104- } \\
31.2008 .8 .26 .0000\end{array}$ \\
\hline Peruíbe/SP & & $\begin{array}{l}\text { Tribunal de Justiça de São Paulo TJ-SP - } \\
\text { Apelação : APL 54967020088260441 SP } \\
\text { 0005496-70.2008.8.26.0441 }\end{array}$ \\
\hline $\begin{array}{l}\text { Pirassunung } \\
\quad \mathrm{a} / \mathrm{SP}\end{array}$ & & $\begin{array}{l}\text { Tribunal de Justiça de São Paulo TJ-SP - } \\
\text { Apelação : APL 57323720098260457 SP } \\
\text { 0005732-37.2009.8.26.0457 }\end{array}$ \\
\hline $\begin{array}{l}\text { Rio de } \\
\text { Janeiro/RJ }\end{array}$ & $\begin{array}{l}\text { Decreto } n^{\circ} 35.648 \text {, de } 16 \text { de maio de } \\
2012\end{array}$ & $\begin{array}{l}\text { Tribunal de Justiça do Rio de Janeiro TJ-RJ } \\
\text { - AGRAVO DE INSTRUMENTO : AI } \\
00110793520048190000\end{array}$ \\
\hline $\begin{array}{l}\text { Araraquara } \\
\quad / S P\end{array}$ & Lei $n^{\circ} 7.733$, de 24 de maio de 2012 & \multirow[t]{2}{*}{ Não identificado } \\
\hline $\begin{array}{l}\text { Monguagá/ } \\
\text { SP }\end{array}$ & $\begin{array}{l}\text { Lei no 2.576, de } 17 \text { de dezembro de } \\
\qquad 2012\end{array}$ & \\
\hline $\begin{array}{l}\text { Pitangueira } \\
\text { S/SP }\end{array}$ & \multirow[t]{2}{*}{ Não identificado } & $\begin{array}{l}\text { Tribunal de Justiça de São Paulo TJ-SP - } \\
\text { Apelação : APL 00027780720128260459 } \\
\text { SP 0002778-07.2012.8.26.0459 }\end{array}$ \\
\hline $\begin{array}{l}\text { Santa } \\
\text { Maria/RS }\end{array}$ & & TJ-RS - Apelação Cível 70055582035 RS \\
\hline $\begin{array}{l}\text { Caraguatat } \\
\text { uba/SP }\end{array}$ & $\begin{array}{c}\text { Lei o } 2.337 \text {, de } 29 \text { de maio de } 2017 \\
\text { Decreto no } 212,11 \\
\text { de dezembro de } 2014\end{array}$ & Não identificado \\
\hline Cássia/MG & Não identificado & TJ-MG - Apelação: 10151140010068001 \\
\hline $\begin{array}{l}\text { Salvador/B } \\
\text { A }\end{array}$ & $\begin{array}{c}\text { Lei no } 8.553 \text {, de } 28 \text { de janeiro de } \\
2014, \\
\text { Lei } n=9.438 \text { de } 2019 \text { e }\end{array}$ & Não identificado \\
\hline
\end{tabular}




\begin{tabular}{|c|c|c|}
\hline & $\begin{array}{c}\text { Decreto no } 25.922, \text { de } 30 \text { de março } \\
\text { de } 2015\end{array}$ & \\
\hline $\begin{array}{c}\text { São } \\
\text { Paulo/SP }\end{array}$ & $\begin{array}{c}\text { Lei no } 16.050, \text { de } 31 \text { de julho de } \\
2014\end{array}$ & \\
\hline Itu/SP & \multirow[t]{2}{*}{ Não identificado } & $\begin{array}{c}\text { TJ-SP - Apelação 1001746- } \\
\text { 76.2015.8.26.0286 }\end{array}$ \\
\hline Salto/SP & & $\begin{array}{c}\text { TJ-SP - Apelação Cível } 1000176- \\
14.2015 .8 .26 .0526\end{array}$ \\
\hline $\begin{array}{c}\text { Vera } \\
\text { Cruz/RS }\end{array}$ & Não identificado & TJ-RS - Apelação 70066889932 \\
\hline $\begin{array}{c}\text { Porto } \\
\text { Alegre/RS }\end{array}$ & $\begin{array}{l}\text { Decreto } 20.341 \text {, de } 23 \text { de agosto de } \\
2019\end{array}$ & Não identificado \\
\hline Juquiá/SP & $\begin{array}{c}\text { Decreto no } 1422 \text {, de } 01 \text { de setembro } \\
\text { de } 2017\end{array}$ & Não identificado \\
\hline $\begin{array}{c}\text { Bragança } \\
\text { Paulista/SP }\end{array}$ & $\begin{array}{c}\text { Decreto } n^{\circ} 2633 \text {, de } 12 \text { de janeiro } \\
\text { de } 2018 \\
\text { Lei } n=4634 \text {, de } 10 \text { de setembro de } \\
2018\end{array}$ & $\begin{array}{l}18 \text { imóveis passíveis do procedimento } \\
\text { (Jan/2018), de acordo com notícia da } \\
\text { Prefeitura. }\end{array}$ \\
\hline $\begin{array}{c}\text { São } \\
\text { Bernardo } \\
\text { do } \\
\text { Campo/SP }\end{array}$ & $\begin{array}{c}\text { Lei no6.691, de } 28 \text { de junho de } 2018 \\
\text { Decreto no } 20.460 \text {, de } 19 \text { de julho } \\
\text { de } 2018\end{array}$ & Não identificado \\
\hline Recife/PE & $\begin{array}{c}\text { Decreto } n^{\circ} 31.671 \text {, de } 10 \text { de agosto } \\
\text { de } 2018\end{array}$ & $\begin{array}{l}\text { Nove imóveis notificados e quatro estão } \\
\text { em processo de notificação (Dez/2019), } \\
\text { de acordo com boletim informativo } \\
\text { Prefeitura. }\end{array}$ \\
\hline $\begin{array}{l}\text { Fernandópo } \\
\text { lis/SP }\end{array}$ & $\begin{array}{l}\text { Decreto no } 8.412 \text {, de } 04 \text { de } \\
\text { setembro de } 2019\end{array}$ & Não identificado \\
\hline $\begin{array}{l}\text { São } \\
\text { Caetano do } \\
\text { Sul/SP }\end{array}$ & $\begin{array}{l}\text { Lei no 5.717, de } 15 \text { de março de } \\
\qquad 2019\end{array}$ & \\
\hline $\begin{array}{c}\text { Nova } \\
\text { Iguaçu/RJ }\end{array}$ & Não identificado & $\begin{array}{c}\text { TJ-RJ - Agravo de Instrumento } 0045563- \\
51.2019 .8 .19 .0000\end{array}$ \\
\hline
\end{tabular}

\section{Avaliação e panorama de efeitos}

Fonte: Autor, 2019.

- O requisito legal de "ausência de possuidor", à princípio, gera a inviabilização do instrumento para diversos imóveis que estavam há anos com a situação de abandono configurada, mas que passaram a ter ocupação irregular pelos movimentos sociais em busca de moradia e que dão uso para o bem. A questão do momento de configuração desse requisito precisa ser cuidadosamente aprofundada, porque pode ser uma solução viável, relativamente rápida e que beneficie muitas famílias. 
- $\quad$ Bruno Santos, Edivaldo Boaventura e Renato Reis (2018, p. 129) alertam que "a existência de um arcabouço legal por si só não é o suficiente para a resolução do problema se não existir uma intencionalidade política clara por parte dos agentes públicos de efetivar tais ações".

- Em matéria de 23 de maio de 2018 disponível no site do Instituto de Registro Imobiliário do Brasil, Cristiana da Costa Nery, ao analisar a situação da Arrecadação de Bem Vago Abandonado em Porto Alegre, alerta que a atuação "certamente, não resolverá a situação da carência de moradias, de equipamentos públicos ou no total uso adequado da propriedade", contudo, este seria "mais um instrumento disponível, auxiliar à gestão eficiente e que deve ser utilizado pelos municípios em benefício da coletividade e do cidadão responsável".

- A Procuradoria Geral Municipal de Porto Alegre/RS (2012), em sede de parecer, afirma ser necessária a ação judicial, o que pode atrasar o cumprimento da função social:

a edição de uma Instrução Normativa, Portaria ou Decreto, com vistas a instituir, no âmbito do executivo municipal, um Grupo de Trabalho (GT) para analisar, precipuamente, os procedimentos internos necessários para se fazer um levantamento de todos os imóveis em condições de abandono, no território do município; verificar todos os imóveis em condições de abandono com dívidas de IPTU, notificações e autuações ao proprietário por infrações às leis municipais e penais; gerenciar todos os expedientes administrativos abertos para tal fim, com vistas à instrução judicial das ações declaratórias de bem vago e arrecadação de imóvel abandonado; encaminhamentos preliminares para a guarda e conservação de bem declarado vago, e assim por diante. Este GT deve ser formado por representantes de todas as Secretarias afins, notadamente a Procuradoria Geral do Município, Secretaria Municipal de Obras e Viação, Secretaria Municipal da Fazenda e Secretaria Municipal do Meio Ambiente. (grifos nossos)

- Merece destaque o exposto acima quanto à instrução judicial. Apesar de não necessitar de autorização judicial para iniciar o procedimento arrecadatório, foi mencionada a ação declaratória, que deve ter como escopo a sentença judicial que declare a imissão da posse, transferência de propriedade e autorização da modificação do registro do bem, de modo a evitar abuso de direito ou insegurança jurídica para a prefeitura e para o proprietário.

- No acervo jurídico federal não existe a obrigação de vínculo da ABVA ao Plano Diretor, o que não impede - e o que deve ocorrer - de existir tal relação, posto que, dada a importância do Plano Diretor na condução do desenvolvimento da cidade, o mesmo poderia prever o direcionamento de uso dos imóveis arrecadados para habitação de interesse social, por exemplo, ou para gerar capital para um fundo habitacional, no caso de alienação. Inclusive, esta segunda 
hipótese precisa ser discutida para saber se a normativa federal que trata da destinação do bem incorporado é taxativa ou exemplificativa.

- Na dissertação de Gasperin (2017, pp. 70 e 71), ao entrevistar o Procurador do Município do Rio de Janeiro, foram levantadas interessantes questões: existem diversos imóveis públicos do próprio município que descumprem a função social e deveriam ter uma destinação; e "arrecadar [imóveis] para fazer o quê?" - reforçando a necessidade de planejamento antes dos procedimentos arrecadatórios. No mesmo trabalho, a autora levanta, através de entrevista com uma defensora pública, a necessidade de vinculação da ABVA à produção da habitação de interesse social (ibid., p.93).

- $\quad$ Segundo a Procuradoria da Fazenda Municipal do Recife ${ }^{22}$, apesar da Lei 13.465/17 prever que "fica assegurado ao Poder Executivo Municipal ou Distrital o direito ao ressarcimento prévio, e em valor atualizado, de todas as despesas em que eventualmente houver incorrido, inclusive tributárias, em razão do exercício da posse provisória" (Art. 64, § $5^{\circ}$ ), durante o lapso temporal de 03 anos do procedimento administrativo arrecadatório, entende-se que se trata de uma atecnia legislativa, já que os impostos decorrentes da posse de imóveis são de competência do município, não havendo, portanto, despesas dessa ordem. Nesse caso, apenas os débitos anteriores à arrecadação continuam a ser cobrados em face do antigo proprietário, ficando desvinculado o futuro proprietário em caso de alienação (em caso de concessão, a propriedade continua com o município).

- Ellen Carvalho (op. cit., p. 119), ao analisar bens culturais ${ }^{23}$ abandonados em Manaus/AM, concluiu que a Arrecadação de Bem Vago Abandonado é um meio eficaz de proteção dos bens culturais ante a ineficiência dada pela salvaguarda do tombamento, mas que depende da implementação de políticas públicas e medidas judiciais para resguardar e proteger o patrimônio e a identidade da cidade.

- No mesmo sentido, Freitas (2006), concluiu que "os imóveis abandonados que exteriorizem valor histórico ou cultural podem ser arrecadados pelos municípios, passando ao seu domínio e assumindo função condizente com a sua situação peculiar".

\footnotetext{
${ }^{22}$ Questionário realizado informalmente em 2018, mas autorizada para publicação.

${ }^{23}$ Identificados como os "portadores de referências importantes na vida de uma comunidade, que neles vê refletida toda uma história de vida pessoal e de seus antepassados" (MIRANDA, 2012, p. 285 apud FREITAS, 2013).
} 
- Farias (2018) afirma que "a arrecadação de bens é mais um instrumento de promoção do direito à cidade, aqui entendido como a garantia de acesso includente e equitativo ao espaço e à infraestrutura urbana".

- A Procuradoria Geral Municipal de Porto Alegre/RS (2012) identifica que "de forma distinta da desapropriação pública", a arrecadação ocorre "independentemente de qualquer indenização ou compensação financeira a quem quer que seja, seja para o proprietário ou para qualquer possuidor direto e de boa fé que esteja no imóvel em momento anterior ao ato de arrecadação".

- A mesma Procuradoria expõe que ela é autoaplicável, sendo desnecessária a exigibilidade de lei própria. O município já pode, ao encontrar imóveis enquadrados nos requisitos legais e respeitando o direito de defesa, agir administrativamente (ou judicialmente).

- Segundo a Procuradoria da Fazenda Municipal do Recife, o instituto alcança imóveis com imunidade tributária, mas a presença de obras, internas e/ou externas, em andamento ou concluídas, presumem o afastamento da configuração do abandono através de uma defesa administrativa ou judicial pela configuração da posse (indireta) e não-abandono do bem, que passou a ser restaurado. Da mesma forma o uso, regular ou irregular, total ou parcial, elimina o requisito legal de "ausência de possuidor", também afastando o instituto, que também não alcança bens públicos.

Visto isso, podemos afirmar que:

a) Quanto às vantagens para a sociedade, destacam-se: (i) segurança jurídica e (ii) cumprimento da função social; (iii) menos burocracia e (iv) mais agilidade que o IPTU Progressivo no Tempo, por exemplo; (v) ausência de gastos indenizatórios (vi) e menor dependência da Câmara Municipal;

b) Quanto às desvantagens para a sociedade, destacam-se: (i) possibilidade de desvio de uso e de finalidade dos imóveis arrecadados; (ii) falta de transparência nos recursos adquiridos com a alienação de bens arrecadados; e (iii) falta de aplicação do instrumento;

c) Quanto às vantagens para o poder público, destacam-se: (i) autonomia administrativa para edição de decreto e de realização do processo de arrecadatório; (ii) segurança jurídica no acervo jurídico consolidado; (iii) possibilidade de reconhecimento de resultados na mesma gestão e (iv) tendência à bons resultados na ABVA; 
d) Quanto às desvantagens para o poder público, destacam-se: (i) possibilidade de desgaste político com a insatisfação do setor imobiliário e por causa da ineficácia dos instrumentos; (ii) falta de amparo normativo em regulamentação municipal; (iii) falta de planejamento e gestão urbanística, com equipe técnica especializada;

e) Quanto às vantagens para o proprietário, destacam-se: (i) segurança jurídica em razão do acervo normativo em vigor;

f) Quanto às desvantagens para o proprietário, destacam-se: (i) obrigação a ser cumprida, sob pena de perda da propriedade; (ii) prazos menores da ABVA, se comparada com o IPTU Progressivo no Tempo;

g) Quanto aos efeitos concretos, a ABVA ainda precisa de mais tempo para ser analisada, posto que não existem registros de casos concretos nos termos das legislações em vigor, apesar de ser vista como positiva em Manaus/AM por Carvalho (2016) e Porto Alegre/RS pela PGMPOA (2012).

\section{CONSIDERAÇÕES FINAIS}

O direito brasileiro, especialmente após a luta pela reforma urbana e após o constitucionalismo social de 1988 , incorporou a função social da cidade e da propriedade como fundamentos que justificam o combate à ociosidade de imóveis, um problema comum a diversas cidades do País, manifestado através dos imóveis não utilizados, imóveis subutilizados e imóveis não edificados, trazendo consigo diversos prejuízos urbanísticos, históricos, sanitários, econômicos etc.

Como forma de instrumentalizar a atuação do poder público municipal para além das necessárias opções ofertadas pelo Estatuto da Cidade - porém já bem debatidas pela doutrina/academia, como o Imposto Predial e Territorial Urbano Progressivo no Tempo - a Arrecadação de Bem Vago Abandonado (ABVA) prevista em 1916 foi reformulada pelo Código Civil de 2002 e reforçada pela Lei $n=13.465 / 17$ e pelo Decreto $n=9.310 / 18$. 
Assim, só recentemente, em um processo de pouco mais de 100 anos de transformações legislativas, deixou de ter o caráter essencial patrimonialista de arrecadação ao poder público e passou a ter perspectiva de chave de promoção da função social porque, após o devido processo legal aqui analisado e ressalvados os direitos de defesa, permite a perda da propriedade privada pelo proprietário de imóvel ocioso, abandonado e com débitos fiscais, passando ao bem arrecadado a ter nova destinação com benefício à sociedade.

Contudo, para que tal aplicabilidade seja eficaz e traga os benefícios elencados neste trabalho - e ainda pouco registrados no Brasil - , os municípios ainda precisam criar/atualizar as disposições legais sobre o tema, conforme observado nas legislações disponíveis e nos julgados sobre o tema (concentrados no Estado de São Paulo). Assim, cabe à iniciativa legislativa popular/poder legislativo/poder executivo municipal atender a devida necessidade.

Não obstante, requer-se uma gestão pública eficiente, capaz de prevenir que o proprietário se aproveite das condições que afastam a aplicabilidade da ABVA (presença de obras, internas e/ou externas, em andamento ou concluídas; uso, regular ou irregular, total ou parcial) e transparente, para evitar desvios de finalidade/recursos oriundos da alienação de bens, interesses políticos/privilégio de determinados sujeitos no uso e ocupação dos bens arrecadados.

\section{REFERÊNCIAS}

\section{Dissertação}

CARVALHO, Ellen Larissa Frota de. Arrecadação de bem vago como instrumento urbanístico eficaz na proteção do patrimônio histórico-cultural do município de Manaus. 25/08/2016 $151 \mathrm{f}$. Mestrado em direito ambiental Instituição de Ensino: Universidade do Estado do Amazonas, Manaus Biblioteca Depositária: PPGDA-UEA. Disponível em: < http://tede.uea.edu.br/jspui/handle/tede/268>. Acesso em 13 jun. 2018.

\section{CLEMENTE, Juliana Carvalho. Vazios urbanos e imóveis subutilizados no centro histórico} tombado da cidade de João Pessoa - PB. 2012. Dissertação de mestrado. Universidade Federal da Paraíba. Programa de pós-graduação em engenharia urbana e ambiental. João Pessoa. Disponível em: < https://repositorio.ufpb.br/jspui/handle/tede/5472?mode=full>. Acesso em 13 jun. 2018.

GASPERIN, Sabrine Tams. Os vazios urbanos e os instrumentos indutores de função social da propriedade e da cidade: um estudo sobre a área central da cidade do Rio de Janeiro. 2017. 242 p. Dissertação (Mestrado em Ciências Jurídicas e Sociais). Programa de Pós-Graduação em Sociologia e Direito - Universidade Federal Fluminense, Niterói, 2017. Disponível em: < https://sucupira.capes.gov.br/sucupira/public/consultas/coleta/trabalhoConclusao/viewTrabalho Conclusao.jsf?popup=true\&id_trabalho=5975210\#>. Acesso em 13 jun. 2018. 
SANHUDO, João Paulo Veiga. A repersonalização da posse no Código Civil de 2002 e uma análise paradigmática com o Código Civil de 1916 à luz de uma releitura hermenêutica-sistemático constitucional. 2007. 124 f. Dissertação (Mestrado em Direito) - Pontifícia Universidade Católica do Rio Grande do Sul, Porto Alegre. Disponível em: < http://tede2.pucrs.br/tede2/handle/tede/4315>. Acesso em 13 jun. 2018.

Livro

DUGUIT, L. Les Transformations générales du Droit privé depuis le Code Napoléon. Libraire Félix Alcan, 1912. Disponível em: < http://gallica.bnf.fr/ark:/12148/bpt6k935172d/f11.image>. Acesso em 13 jun. 2018.

FORNEROLLI, L. A função social da propriedade imóvel privada: o aproveitamento adequado do solo urbano. Florianópolis: Conceito Editorial, 2014.

GONÇALVES, Carlos Roberto. Direito Civil: direito das coisas. São Paulo: Saraiva, 2002.

GRAU, Eros Roberto. A ordem econômica na Constituição de 1988. São Paulo: Malheiros, 2ª ed., 2001.

LEFEBVRE, Henry. O direito à cidade. Tradução de Rubens Frias (Original: Le droit à la ville, 1967) São Paulo: Editora Moraes, 1991.

Capítulo de livro

MARICATO, Ermínia. Autoconstrução, a arquitetura possível. In: A produção capitalista da casa (e da cidade) no Brasil industrial. São Paulo: Alfa-Omega, 1979. Disponível em: < https://erminiamaricato.files.wordpress.com/2012/03/a-produccca7acc83o-capitalista-da-casa-eda-cidade-no-brasil-industrial.pdf>. Acesso em 13 jun. 2018.

GARCIAS, C.; BERNARDINI, J. As funções sociais da cidade. Revista Direitos Fundamentais e Democracia, v. 4, 2008. Disponível em: <

http://revistaeletronicardfd.unibrasil.com.br/index.php/rdfd/article/viewFile/48/47>. Acesso em: 13 jun. 2018.

MOTA, M. A natureza jurídica do art. $1228, \S \S 4^{\circ}$ e 50 do Código Civil: exceção de não funcionalização social do domínio. Empório do Direito, 29 mar. 2017. Disponível em: <http://emporiododireito.com.br/leitura/a-natureza-juridica-do-artigo-1228-4-e-5-do-codigocivil-excecao-de-nao-funcionalizacao-social-do-dominio-por-mauricio-mota>. Acesso em: 13 jun. 2018.

TAVOLARI, Bianca. Direito à cidade: uma trajetória conceitual. Novos Estudos, ed. 104, v. 35, n.1, mar. 2016. Disponível em: <http://cidadeseducadoras.org.br/wp-

content/uploads/2018/03/Direito_a_cidade_uma_trajetoria_conceitu.pdf $>$. Acesso em: 13 jun. 2018.

Outras publicações acadêmicas

CARVALHO, Antonio Marcos Ximenes. A institucionalidade da presunção absoluta do Art. 1276, $\S 2$ ㅇ do Código Civil para a perda da propriedade por abandono. Arcos. Disponível em: < http://www.arcos.org.br/artigos/a-institucionalidade-da-presuncao-absoluta-do-art-1276- 
paragrafo2o-do-codigo-civil-para-a-perda-da-propriedade-por-abandono/>. Acesso em: 13 jun. 2018.

CUNHA, Leandro; DOMINGOS, Terezinha. A perda da propriedade imóvel em razão do abandono e o capitalismo humanista. Anais. XIX Encontro Nacional do CONPEDI, Forteleza, 2010, pp. 2341-2350. Disponível em: <

http://www.publicadireito.com.br/conpedi/manaus/arquivos/anais/fortaleza/3523.pdf $>$. Acesso em: 13 jun. 2018.

FARIAS, Cristiano Chaves de Farias. O calvário do \$2 do art. 1.276 do Código Civil: vida e morte de um malfadado dispositivo legal a partir de uma interpretação constitucional. 2015. Disponível em: <http://www.linselins.com.br/wpcontent/uploads/2015/11/artinconstitucionalidadeCC1276.pdf>. Acesso em: 13 jun. 2018.

FARIAS, Talden. Abandono de imóveis urbanos e a responsabilidade dos municípios. Consultor Jurídico: 2018. Disponível em: <https://www.conjur.com.br/2018-mai-05/ambiente-juridicoabandono-imoveis-urbanos-responsabilidade-municipios\#_ftn8>. Acesso em: 13 jun. 2018.

FREITAS, Vladimir Passos de. A perda da propriedade abandonada com valor histórico. Ministério Público do Estado de Minas Gerais. 2013. Disponível em:

<https://aplicacao.mpmg.mp.br/xmlui/bitstream/handle/123456789/1152/16\%20R\%20MJ\%20\%20Perda\%20da\%20propriedade\%20-\%20Vladimir.pdf?sequence=1>. Acesso em 13 jun. 2018.

LOTTI, Armando. Abandono de bem imóvel e a derrelição presumida. XXXIII Encontro dos Oficiais de Registro de Imóveis do Brasil. Boletim eletrônico. IRIB n. 2663, 22 set. 2006. Disponível em: $<$ http://www.serjus.com.br/noticias_antigas/on-

line/abandono_bem_imovel_derrelicao_presumida_25_09_2006.html>. Acesso em 13 jun. 2018.

SANTOS, Bruno Oliveira; et. al. Alternativas legais para a apropriação de imóveis abandonados: um estudo de caso no município de Salvador/BA. Revista de Direito da Cidade, v. 10, no 1, pp. 95-132. Disponível em: < http://www.e-publicacoes.uerj.br/index.php/rdc/article/viewFile/29621/23338>. Acesso em: 13 jun. 2018.

\section{Legislação}

ALEMANHA. Constituição (1919). Promulgada em 11 de ago. de 1919. Weimer: 1919. Disponível em: <https://www.btg-bestellservice.de/pdf/80208000.pdf>. Acesso em 13 jun. 2018.

BRASIL. Conselho da Justiça Federal. Enunciado n² 242. Brasília, DF: 2006.

. Conselho da Justiça Federal. Enunciado n² 243. Brasília, DF: 2006.

. Constituição (1988). Promulgada em 5 de out. de 1988. Congresso Nacional.

Brasília, DF: 1988.

. Lei $n^{\circ} 3.071$, de $1^{\circ}$ de jan. de 1916. Código Civil. Congresso Nacional: Rio de Janeiro, 1916.

1919.

. Decreto do Poder Legislativo no 3.725, de 1919. Congresso Nacional: Rio de Janeiro, 
. Lei $n^{\circ}$ 6.969, de 10 de dezembro de 1981. Congresso Nacional. Brasília, DF: 2001.

. Lei $n^{\circ}$ 10.257, de 10 de jul. de 2001. Estatuto da Cidade. Congresso Nacional. Brasília, DF: 2001.

. Lei n 10.406, de 10 de jan. de 2002. Código Civil. Congresso Nacional. Brasília, DF: 2002.

. Lei $n^{\circ} 13.465$, de 11 de jul. de 2017. Lei da Regularização Fundiária Urbana, Rural e na Amazônia Legal. Congresso Nacional. Brasília, DF: 2017.

. Decreto no 9.310, de 15 de março de 2018. Decreto da Regularização Fundiária Urbana, Rural e na Amazônia Legal. Congresso Nacional. Brasília, DF: 2018.

MÉXICO. Constituição (1917). Promulgada em 5 de fevereiro de 1917. Disponível em <http://www.wipo.int/edocs/lexdocs/laws/es/mx/mx139es.pdf>. Acesso em 13 jun. 2018.

\section{Outros}

AQUINO, Tomás de. Suma Teológica. II. II. v. 6. São Paulo: Edições Loyola, 2005, q. 66, 1.

BRAJATO, D.; DENALDI, R. Parcelamento, Edificação e Utilização Compulsórios e IPTU

Progressivo no Tempo : Caderno Técnico de Regulamentação e Implementação. Brasília:

Ministério das Cidades, 2015. Disponível em: <

http://www.capacidades.gov.br/media/doc/acervo/24913341eba9a5572ee3fcede9855a81.pdf>.

Acesso em 14 jun. 2018.

FREITAS, Vladimir Passos de. A perda da propriedade abandonada com valor histórico. Ministério

Público do Estado de Minas Gerais. 2013. Disponível em: <https://aplicacao.mpmg.mp.br/xmlui/bitstream/handle/123456789/1152/16\%20R\%20MJ\%20\%20Perda\%20da\%20propriedade\%20-\%20Vladimir.pdf?sequence=1>. Acesso em 13 jun. 2018.

HARVEY, David. 0 direito à cidade. Revista Piauí, jul. 2013, edição no 82, 2013. Disponível em: < https://piaui.folha.uol.com.br/edicao/82/>. Acesso em 14 jun. 2018.

JOÃO PAULO II, Papa.Carta Encíclica Centesimus Annus (centenário da Rerum Novarum). São Paulo: Loyola, 1991.

LEÃO XIII, Papa. Carta Encíclica Rerum Novarum (sobre a condição dos operários). São Paulo: Loyola, 1991.

LE CORBUSIER. Carta de Atenas. 1933. Tradução: Rebeca Scherer. São Paulo.

NERY, Cristina. $O$ abandono de imóveis deve ser combatido. 2018. Disponível em: $<$ http://www.irib.org.br/noticias/detalhes/artigo-o-abandono-de-imoveis-deve-ser-combatidoundefined-por-cristiane-da-costa-nery>. Acesso em: 13 jun. 2018. 
SÃO PAULO. Prefeitura. Cartilha da Função Social da Propriedade. São Paulo: 2014. Disponível em:< https://gestaourbana.prefeitura.sp.gov.br/noticias/prefeitura-disponibiliza-cartilha-dafuncao-social-da-propriedade/>. Acesso em $18 \mathrm{dez} .2019$.

PORTO ALEGRE. Procuradoria Geral do Município. Parecer PDA/PGAAF/PGM N¹.175/2012. Disponível em:

<http://www.urbanismo.mppr.mp.br/arquivos/File/PGMPOAParecer2012_arrecadacao_imovel_a bandonado.pdf >. Acesso em 14 jun. 2018.

Trabalho enviado em 06 de janeiro de 2020

Aceito em 23 de abril de 2020 